\title{
Evaluation of Depressant Activity on Mansoa alliacea on Rats
}

\author{
Nayudu Teja ${ }^{1}$, Ooha Deepika Gummadi ${ }^{*}$, Bolla Valli Devi ${ }^{2}$ and Naidu \\ Pavani $^{2}$ \\ ${ }^{1}$ Department of Pharmaceutics, V.V Institute of Pharmaceutical Sciences, Gudlavaleru, \\ Andhra Pradesh, India \\ ${ }^{2}$ Department of Pharmacy, V.V Institute of Pharmaceutical Sciences, Gudlavaleru, \\ Andhra Pradesh, India \\ *Corresponding Author: Ooha Deepika Gummadi, Department of Pharmaceutics, \\ V.V Institute of Pharmaceutical Sciences, Gudlavaleru, Andhra Pradesh, India.
}

Received: September 03, 2020

Published: October 16, 2020

(C) All rights are reserved by Ooha Deepika

Gummadi., et al.

\begin{abstract} than moods. There are a few most common physical symptoms of depression:

- Increased body pains, which is seen mostly in two out of three people with depression.

- $\quad$ Severe fatigue.

- Lack of interest in sex.

- Loss of appetite.

- Insomnia, lack of deep sleep or oversleeping.

Keywords: Depression; Norepinephrine (NE); Dopamine (DA); Mansoa alliacea
\end{abstract}

Depression is a serious medical illness that aggravates the negative feelings of a person that causes changes in their behaviour and thinking process. It is characterised by persistently low mood and/or loss of interest in daily activities. It leads to variety of emotional and physical problems can decrease a person ability to function at work and home. The major hypothesis of depression was primarily demonstrated 30 years ago in which it is stated that the prominent symptoms of depression are caused due to the functional deficiency of the brain monoaminergic transmitter's norepinephrine (NE), 5-HT and/or dopamine (DA). Depression affects much more

\section{Introduction}

The Mansoa alliacea, or garlic vine, is a species of tropical liana in the family of Bignoniaceae. This plant contains different pharmacological activities; they are anti-inflammatory activity, antibacterial activity, anti-arthritic activity, anti-oxidant activity and also anti-depressant activity. Depression is a clinical condition characterised with persistent mood of feeling low or loss of interest in daily activities. It may be outcome of biological, psychological and social sources of distress. This occurs due to the functional deficiency of monoaminergic transmitter's like norepinephrine, 5-HT and dopamine.
Medicinal plants are also known as medicinal herbs, have been used in traditional medicine since ancient times. Plants synthesize numerous chemical compounds for protecting themselves from insects, fungi, diseases and herbivorous mammal. Through recent researches, plant-derived drugs were reliably discovered from the traditional cures and most especially the folk knowledge of indigenous people. Although there are many synthetic drugs existing for the treatment of depression, it is necessary to do rigorous research on herbal compounds which are compatible to the human body due to their natural origin [1-15]. 
Aim of the Study

The aim of that present study is to evaluate one such natural compound, Mansoa alliacea for its anti-depressant activity on rats.

\section{Materials and Methods}

\section{Identification and collection of plant material}

The whole plant of Mansoa alliacea was collected from surrounding area of Gudlavalleru and Gudivada. These leaves were identified and authenticated by the Department of Botany Hindu college, Machilipatnam. The leaves and flowers are sorted, cleaned air dried at room temperature for one week. Then it was ground powder. Powdered sample was collected and stored in air and water proof containers protected from direct sunlight and heat until used for extraction.

\section{Preparation of extract by using soxhlet apparatus}

The powdered material of Mansoa alliacea was extracted for $24 \mathrm{hrs}$ with spirit in soxhlet apparatus. The extracts were concentrated to dryness till free from the solvents.

\section{Phytochemical analysis}

Phytochemical analysis of extract was carried out for the presence of alkaloids, glycoside, flavonoids, tannins, saponins, steroids, terpenoids, etc. by different methods.

\section{Tests for saponin}

- Foam test: A small amount of extract is shaken with little quantity of water. The foam produced persists for $10 \mathrm{~min}$ utes. It confirms the presence of saponins.

- Hemolysis test: To $2 \mathrm{ml}$ normal saline in 2 test tubes, $2 \mathrm{ml}$ distilled water is added to one and two $\mathrm{ml}$ of $1 \%$ extract to the other five drops of blood is added to each test tube and gently mixed with content. Hemolysis observed under the microscope in the test tube containing the extracts indicates the presence of saponins.

\section{Tests for tannins}

- $\quad$ Ferric chloride test: Extracts mixed with 1\% ferric chloride solution gives blue, green or brownish green color.

- Gelatin test: Extracts mixed with few drops of $1 \%$ solution of gelatin containing $10 \%$ sodium chloride gives white precipitate.

\section{Tests for flavonoids}

- $\quad$ Ferric chloride test: Alcoholic solution of the extracts mixed with few drops of neutral ferric chloride solution gives green color and yellow precipitate.
- Lead acetate test: Alcoholic solution of the extracts mixed with few drops of $10 \%$ lead acetate gives white color precipitate.

Tests for alkaloids

- The extracts were mixed with ammonia and then extracted with chloroform solution. To this dilute hydrochloride acid was added. The acid layer was used for chemical tests for alkaloids.

- Mayer's test (Potassium mercuric iodide): The acid layer with few drops of Mayer's reagent gives a creamy white precipitate.

- Wagner's test (Solution of iodine in potassium iodide): The acid layer with few drops of Wagner's reagent gives reddish brown colored precipitate.

- Hager's test (Saturated solution of picric acid): The acid layer with hanger's reagent gives yellow precipitate.

- Dragendroff's test (Solution of potassium bismuth iodide): Acid layer with few drops of Dragendroff's reagent gives reddish brown precipitate.

\section{Tests for glycosides}

- $\quad$ Sodium hydroxide reagent: Dissolve a small amount of alcoholic extract in $1 \mathrm{ml}$ water and add sodium hydroxide solution. A yellow color indicates the presence of glycosides.

- Kellarkillani's test: Dissolve the extract in water with glacial acetic acid band ferric chloride and concentrated sulphuric acid. They give brown ring bat the junction.

- $\quad$ Picrate paper test (for cyanogenic glycosides): Extracts are added with few drops of chloroform and concentrated sulphuric acid. The test tube is tightly stopped with picrate paper protruding into the test tube when kept on water bath, positive sample turns yellow picrate paper into red.

\section{Test for steroids}

- Salkowaski test: Chloroform solution of the extract when shaken with concentrated sulphuric acid and on standing yields red color.

- Lieberman burchard test: To chloroform solution of the extract with few drops of acetic acid anhydride add one ml of concentrated sulphuric acid from the sides gives reddish ring at the junction of 2 layers.

\section{Test for carbohydrates}

- Molisch's test: This is a common test for all carbohydrates larger than tetroses. The test is done on the basis that pentoses and hexoses are dehydrated by Con. Sulphuric acid to form furfural or hydroxymethylfurfural, respectively. These products condense with $\alpha$-naphthol to form purple condensation product. 
- $\quad$ Fehling's test: This forms the reduction test of carbohydrates. Fehling's solution contains blue alkaline cupric hydroxide solution, heated with reducing sugars gets reduced to yellow or red cuprous oxide and is precipitated. Hence, formation of the yellow or brownish-red colored precipitate helps in the reduction of reducing sugars in the test solution.

- Benedict's test: As in Fehling's test, free aldehyde or Keto group in the reducing sugars reduce cupric hydroxide in alkaline medium to red color cuprous oxide. Yellow to green color is developed. The intensity of colour depends on the concentration of sugars. All monosaccharides are reducing sugars as they all have a free reactive carbonyl group. Some disaccharides, like maltose, have exposed carbonyl groups and also reducing sugars, but less reactive than monosaccharides.

Tests for proteins

- $\quad$ Biuret test: Biuret solution is a blue liquid that changes to purple when proteins are present and to pink in the presence of short chain polypeptides. The copper atom of the biuret solution reacts with the peptide bonds that causes change in colour.

Test for phenols

- $\quad$ Ferric chloride test: Treatment of $1 \% \mathrm{Fecl}_{3}$ in $\mathrm{CHCl}_{3}$ with a phenol yields a tri aryl oxy complex. This reagent is useful for detecting the presence of a hydroxyl group attached directly to an aromatic nucleus, alcohols do not undergo this reaction most phenols yields intense red, blue, purple, or green colorations in the ferric chloride test.

- Bromine water test: Phenols react rapidly with bromine water to produce insoluble substances. All available positions i.e. ortho-para to the phenols are brominated. The bromine color is rapidly discharged and eventually the insoluble 2,4,6-tribromo phenol will precipitate out.

\section{Experimental animals}

Animals (Wister albino mice) were divided into various groups such that each group has 6 animals. Animals were treated with 5\% Gum Acacia Suspension (0.1 ml p.o.) served as control, Diazepam ( $2 \mathrm{mg} / \mathrm{kg}$ i.p.) served as standards and animals in test group were treated with Mansoa alliacea leaves ethanolic extract $(400 \mathrm{mg} / \mathrm{kg}$ i.p.) respectively. Each animal was treated with their respective drug 30 minutes before experimentation. Following are the details of experiments performed in below.

\section{Actophotometer test}

The locomotor behavior of animal was monitored using an experimental instrument called actophotometer. Animals were placed in actophotometer individually, and basal activity score was recorded for about 5 minutes. Each animal was treated with respective drug, and activity score was recorded for every 30 minutes upto $1 \mathrm{~h}$. Decreased activity score was taken as suggestive of CNS depression.

\section{Rotarod apparatus}

Four animals were placed on rod rotating with a speed of 20 $25 \mathrm{rpm}$ at a time. Only the mice that demonstrated their ability to remain on the revolving rod (20 - $25 \mathrm{rpm}$ ) for 5 minutes after training sessions during pretest screening were selected for studies. The fall off time was recorded in all the groups 30 minutes prior and 30 minutes after drug administration. Decrease in fall off time suggests the depression of the central nervous system (CNS).

\section{Preliminary phytochemical analysis}

Phytochemical analysis of aqueous extract of Mansoa alliacea whole plant showed the presence of compounds (Table 1), such as flavanoids, alkaloids, proteins, carbohydrates, steroids, tannins.

\begin{tabular}{|c|c|c|c|}
\hline S. no & Phytochemicals & Tests & Result \\
\hline 1 & Saponins & Frothing test & + \\
\hline 2 & Tannins & $\mathrm{FeCl}_{3}$ & + \\
\hline 3 & Flavanoids & $\mathrm{NaOH}$ Test & + \\
\hline 4 & Alkaloids & Dragandroff's test & + \\
\hline 5 & Glycosides & Keller kiliani test & + \\
\hline 6 & Steroids & Libermann-Burchard test & + \\
\hline 7 & Carbohydrates & Molisch's test & + \\
\hline 8 & Proteins & Biuret test & + \\
\hline 9 & Phenols & Ferric chloride test & + \\
\hline
\end{tabular}

Table 1: Phytochemical screening of chloroform extract of Mansoa alliacea leaves.

Assessment of depressant activity of different extract of Mansoa alliacea

1. Rota-rod method and actophotometer test: Diazepam (2 $\mathrm{mg} / \mathrm{kg}$ ) and ethanolic extract of Mansoa alliacea (400 mg/ $\mathrm{kg}$ ) treated groups showed significant CNS depressant activity when compared to control however this depression was less with ethanolic extract of Mansoa alliacea treated group than diazepam treated group.

2. Open field test: Diazepam $(2 \mathrm{mg} / \mathrm{kg})$ and ethanolic extract of Mansoa alliacea (400 mg/kg i.p.) prominently ( $p<0.001$ ) showed anxiolysis evidenced by increased ambulation, rearing and preening at the same time decreased defecations compared to control. 


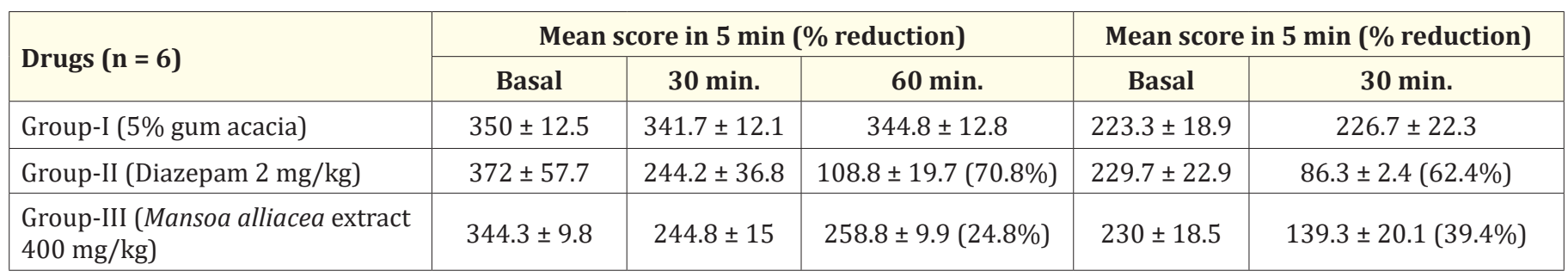

Table 2: Activity scores in actophotometer method and mean fall off time using Rota-rod method.

\section{Conclusion}

Based upon the results obtained in the present study, it is concluded that ethanolic extract of Mansoa alliacea contains considerable amount of saponins, flavanoids, tannins, alkaloids, glycosides, carbohydrates and phenolic compounds exhibits depressant activity. It was proved that the ethanolic extract from Mansoa alliacea has depressant activity, which might be helpful in reducing anxiety.

\section{Acknowledgement}

Authors are sincerely thankful to V.V institute of pharmaceutical sciences, Gudlavaalleru for providing necessary facilities for carry out research work.

\section{Bibliography}

1. "Numbers of threatened species by major groups of organisms (1996-2010)". International Union for Conservation of Nature (2010).

2. Field CB., et al. "Primary Production of the biosphere: Integrating terrestrial and oceanic Components". Science 281.5374 (1998): 237-240.

3. Krek M. "Enigma of the First Arabic Book Printed from Movable Type”. Journal of Near Eastern Studies 38.3 (1979): 203212.

4. Britannica Online Encyclopedia (2009).

5. Smith AL. "Oxford dictionary of biochemistry and molecular biology". Oxford University Press (1997).

6. Rabin Witch E and Govindjee. "Photosynthesis". Wiley, London (1969).

7. Ahn K. "The worldwide trend of using botanical drugs and strategies for developing global drug". BMB Reports 50.3 (2017): 111-116.

8. Sandberg F and Corrigan D. "Natural Remedies". Their Origins and Uses. Abingdon: Taylor and Francis (2001).
9. Schulz V., et al. "Rational Phototherapy". A Physician's Guide to Herbal Medicine. $4^{\text {th }}$ edition. Berlin: Springer-Verlag (2001): 306.

10. Calixto JB. "Efficacy, safety, quality control, marketing and regulatory guidelines for herbal medicines (phytotherapeutic agents)". Brazilian Journal of Medical and Biological Research 33.2 (2000): 179-189.

11. Arsdall Anne V. "Medieval Herbal Remedies: The Old English Herbarium and Anglo-Saxon Medicine". Psychology Press (2002): 70-71.

12. Mills Frank A. "Botany". In Johnston, William M. (edition.). Encyclopedia of Monasticism: M-Z. Taylor andamp; Francis (2000): 179.

13. Ramos-e-Silva Marcia. "Saint Hildegard Von Bingen (10981179); The Light of Her People and of Her Time". International Journal of Dermatology 38.4 (1999): 315-320.

14. Castleman Michael. The New Healing Herbs. Rodale (2001): 15.

15. Singer Charles. "Herbals". The Edinburgh Review 237 (1923): 95-112.

\section{Assets from publication with us}

- Prompt Acknowledgement after receiving the article

- Thorough Double blinded peer review

- Rapid Publication

- Issue of Publication Certificate

- High visibility of your Published work

Website: www.actascientific.com/

Submit Article: www.actascientific.com/submission.php Email us: editor@actascientific.com

Contact us: +919182824667 